\title{
Maximum Economic Yield Fishery Management in the Face of Global Warming
}

\author{
Diop Bassirou ${ }^{1,{ }^{*}}$, Sanz Nicolas ${ }^{2}$, Duplan Yves Jamont Junior ${ }^{3}$, Guene El Hadji Mama ${ }^{4}$, \\ Blanchard Fabian ${ }^{5}$, Pereau Jean-Christophe ${ }^{6}$, Doyen Luc ${ }^{6}$
}

${ }^{1}$ CNRS (French National Centre for Scientific Research), UMRS 3456, LEEISA, Domaine de Suzini, BP 477, Cayenne 9733, French Guiana

2 University of French Guiana, UMRS 3456, LEEISA, Campus Troubiran, BP 20792, Cayenne 97337 , French Guiana

${ }^{3}$ University of French Guiana, Campus Troubiran, BP 20792, Cayenne 97 337, French Guiana

${ }^{4}$ IPR-Institute of Physics of Rennes, France

${ }^{5}$ Ifremer (French Research Institute for Exploitation of the Sea), UMRS 3456, LEEISA, Domaine de Suzini, BP 477, Cayenne 97331, French Guiana

${ }^{6}$ GREThA CNRS (French National Centre for Scientific Research), University of Bordeaux, Avenue Léon Duguit, Pessac 33608, France

*Corresponding author : Bassirou Diop, email address : diop.bassirou@gmail.com

\begin{abstract}
:
This paper deals with fishery management in the face of the ecological and economic effects of global warming. To achieve this, a dynamic bioeconomic model and model-based scenarios are considered, in which the stock's growth function depends on the sea surface temperature. The model is empirically calibrated for the French Guiana shrimp fishery using time series collected over the period 1993-2009. Three fishing effort strategies are then compared under two contrasted IPCC climate scenarios (RCP 8.5 and RCP 2.6). A first harvesting strategy maintains the Status Quo in terms of fishing effort. A more ecologically-oriented strategy based on the closure of the fishery is also considered. A third strategy, which relates to Maximum Economic Yield (MEY), is based on the optimisation of the net present value derived from fishing. The results first show that 'Status Quo' fishing intensity combined with global warming leads to the collapse of the fishery in the long run. Secondly, it turns out that the Closure strategy preserves stock viability especially under the optimistic climate scenario. Thirdly, the MEY strategy makes it possible to satisfy bioeconomic performances requirements with positive stock and profit, once again, especially under the optimistic warming scenario. Consequently, MEY emerges as a relevant bioeconomic strategy in terms of adaptation to climate change but only in connection with climate change mitigation.
\end{abstract}

Keywords : Renewable resources, Fishery bioeconomic model, Climate change, Climate scenarios, Adaptation, Shrimp 


\section{Introduction}

Marine biodiversity and ecosystems are under pressure worldwide. According to Moffitt and Cajas-Cano (2014), around 25\% of world's commercial fish species are overexploited. Climate change complicates and exacerbates the issues by inducing new -or intensifying existing- risks, uncertainties and vulnerabilities.

Recognition that global warming affects the ecological functioning of marine ecosystems and fisheries is increasing. Lehodey et al. (2006), Steinmetz et al. (2008) and Garza-Gil et al. (2011) analyse the effects of climate on fisheries. More specifically, Brander (2007) and Cheung et al. (2009) argue that climate change and global warming, in particular through their effect on sea temperature, may be the strongest drivers of stock dynamics and harvest levels in the future. As rapid and persistent rises in temperature are expected to occur during the next decades (Levitus et al., 2000), there is a clear need to take this phenomenon into account in management strategies and public policies.

In that context, the European Union explicitly includes the objectives of climate change mitigation and adaptation in its policy relating to maritime spatial planning and integrated coastal zone management. Thus, the Common Fisheries Policy (Reg. UE 1380/2013 11/12/2013) reaffirms the obligations associated with international commitments on sustainable management of fisheries. It also puts forward a more regional approach for optimising various ecological and socio-economic objectives in order to reach, in particular, Maximum Sustainable Yileds (MSY) by 2020. Positive economic and social benefits as well as food security are also targeted. Moreover, the Marine Strategy Framework Directive (MSFD), which requires "Good Environmental Status" including descriptors on biodiversity (gains in fish community, status of the assessed stock, indicators of individual size, etc.) has to be applied as well. This is challenging for the EU overseas entities, where to date the MSFD has not been applied.

As a consequence of the above-mentioned difficulties, designing quantitative tools to guide public policies and ensure the long-term bioeconomic sustainability and resilience of marine fisheries in the face of global warming is a major challenge (Moffitt and Cajas-Cano, 2014). In response, an increasing number of marine scientists and 
experts advocate the use of ecosystem-based fishery management (EBFM) which takes into account the various ecological and economic complexities involved, including habitat and climate drivers (Pikitch et al., 2004; Thébaud et al., 2014; Link et al., 2017; Doyen et al., 2017). However, operationalising the EBFM approach remains difficult (Sanchirico et al., 2008; Doyen et al., 2017) especially from a bioeconomic viewpoint. In particular, question arises as to how to adapt current management strategies including MSY when adopting an ecosystem approach. Many fish stocks are currently managed to reach their MSY, through limitations on fishing quotas or effort (Mace, 2001; Worm et al., 2009; Yimin et al., 2013). At MSY, catches are maximised at levels where stocks can regenerate. However, the sustainability of this monospecific strategy is disputed (Larkin, 1977). Instead of MSY, many resource economists advocate the use of maximum economic yield (MEY) targets, at which profits are maximised (Dichmont et al., 2010). Although it depends on the discount rate, the sensitivity of costs and revenues to biomass and harvest, and the marginal growth of the biomass, harvesting at MEY may favour higher biomass levels than MSY, for instance in the case of zero discounting (Grafton et al., 2007; Clark, 2010). Adopting the MEY management strategy may lead to a win-win outcome under frictionless conditions even when the discount rate is much higher than the intrinsic growth rate of fish (see Grafton et al., 2007, 2010), and when onshore sectors (retailing, fishing processing) are incorporated (Grafton et al., 2012). MEY was chosen as a reference point for Australian fisheries. However, the extent to which MEY management can be adapted to climate change and more globally to the ecosystem approach remains an open question.

The aim of this paper is to explore fishery management in the face of the ecologicaleconomic effects of global warming and in particular to evaluate the bioeconomic merits of MEY policies for operationalising ecosystem-based management of fisheries confronted with climate change. In order to do so, we analyse the case of the French Guiana shrimp fishery (FGSF), a challenging task since, despite major reductions in fishing effort and harvest levels over the past two decades, the shrimp stock continues to decrease, which suggests that other factors may have a stronger influence on that fishery. Accordingly, the dynamic bioeconomic model developed in this paper considers that the shrimp stock's growth function depends on sea surface temperature (SST), as suggested in Sanz et al. (2017).

The natural growth and harvest functions of the bioeconomic model of the FGSF are estimated using catch and effort time series collected by Ifremer (French Research Institute for Exploitation of the Sea) over the period 1993-2009. We then compare the bioeconomic performance of three management strategies under two distinct IPCC (Intergovernmental Panel on Climate Change) climate scenarios (RCP 2.6 and RCP 8.5) for the period 2010-2050. These strategies include maintaining the Status Quo in fishing effort, the Closure of the fishery and a third strategy relating to (dynamic or discounted) MEY through the optimisation of the net present value derived from fishing.

The paper is organised as follows: Section 2 describes the FGSF in greater detail, no- 
tably concerning its institutional context. Section 3 presents the bioeconomic model, its calibration, and the climate scenarios as well as the three distinct management strategies. Section 4 focuses on the results of the simulations over the period 2010-2050, Section 5 discusses the results, and Section 6 presents some concluding remarks and prospects.

\section{The French Guiana shrimp fishery}

After being the most highly traded fishery product for decades on a global scale, shrimp nowadays still ranks second in terms of value. Shrimp is mainly produced in developing countries, and much of this production enters international trade (FAO, 2016). For French Guiana, the shrimp fishery constitutes a major source of value: it represents the third largest export sector (25\% of the total volume) (Garandeau, 2006). The FGSF targets two species, brown and pink shrimp (Farfantepenaeus subtilis and Farfantepenaeus brasiliensis). Fishing activities in the FGSF started in the late 1960's with US and Japanese fleets, which gradually became French between 1970 and 1990. Since 1992, the fleet has been made up solely of French trawlers targeting shrimp on the continental shelf

From 1992 to 1999, shrimp stock assessments of shrimps were performed by a working group within the institutional and international framework of the FAO's Western Central Atlantic Fishery Commission (WECAFC). Since 1999, stock assessments to provide management advice have been carried out by Ifremer. The method used for assessments carried out on a monthly basis is the "Virtual Population Analysis" (VPA) which enables recruitment and abundance as well as spawning stock biomass and fishing mortality to be determined.

Management rules were gradually adopted for the FGSF, starting with the creation of the Exclusive Economic Zone in 1977. In 1983, a Total Allowable Catch (TAC) system was implemented for both brown and pink shrimp, in particular to comply with European legislation. This TAC is calculated on the basis of MSY by combining a Schaefer production model and size structure statistics. Initially set at 4,108 tonnes, including 108 tonnes allocated to neighbouring countries (Suriname, Trinidad, Barbados), it remained unchanged until 2011. Moreover, in 1991, a licensing system aimed at limiting the number of trawlers was introduced for both species. Licences are managed by the French Ministry of Agriculture and Fisheries and are issued free of charge. The TAC is set by the European Union. In terms of regulations, there also certain spatial restrictions: in order to limit the impact of trawling on juvenile shrimp and avoid conflicts with the small-scale coastal fishery, trawling is forbidden in coastal waters less than 30 metres deep. This rule is more restrictive than the spatial limitation applied to trawlers in European waters.

Despite these different regulations and management rules, the FGSF has faced many 
difficulties for the past two decades. Shrimp stock has decreased since 1993, while the economic dynamics of the fishery has been characterised by a reduction in fleet size, with fishing activities currently concentrated among a small number of profitable vessels (around 10). Other difficulties include the fact that the TAC has never been fully reached. Similarly, the licensing system also has not been useful since the number of active shrimp trawlers is smaller than the number of available licences. The high variability of stock recruitment (Béné and Doyen, 2000), globalisation of the shrimp market (which has led to a 50\% decrease in real prices since 1997), and long-term increases in fuel prices worldwide, as well as the 2007 financial crisis, partly explain the economic problems of the fishery. However, the decline of the shrimp stock despite the significant reduction in fishing effort and harvest levels for two decades suggests that other factors may have a stronger influence on the FGSF. Among those drivers, Sanz et al. (2017) focus on environmental factors, and show that sea surface temperature (SST), together with river flow rates and El Niño and La Niña phenomena, affect the quality of offshore waters and thus the productivity of the local marine ecosystem. The French Guiana marine fishing area might indeed be affected by changes in SST since the latter significantly increased between 1970 and 2004 along the Guianese coast. The difference between the average values of these two periods is estimated at $0.65^{\circ} \mathrm{C}$, with an accentuation of this phenomenon since 1995 (Bernard, 2006).

Consequently, this paper investigates the ecological and economic effects of ocean warming on the FSFG. To achieve this, a dynamic bioeconomic model, in which shrimp's growth function depends on SST is calibrated. The empirical quantification of the model combines climate and shrimp fishery data over the period 1993-2009. SSTs were provided by the National Climatic Data Center (NCDC) database. The data cover the area between $2-9^{\circ} \mathrm{N}$ and $47-59^{\circ} \mathrm{W}$. The analysis used buoy and ship data sets, as well as satellite sea surface temperature data. Fishing effort and stock data were derived from the Ifremer information system ${ }^{1}$. From the calibrated model, both exploratory and normative fishing scenarios are combined with IPCC climate scenarios (RCP 2.6 and RCP 8.5) at the time horizon 2050. Regarding fishing strategies, attention is paid to the MEY strategy due to its potential ecological-economic merits as compared to MSY.

\section{The bioeconomic model}

This section presents the bioeconomic and ecosystem model for the FGSF. First, the shrimp's natural growth function and its calibration with a data set covering the period 1993-2009 are presented, followed by the fishery production function and its calibration with a 1993-2009 time series. Then, the different fishing strategies and the climate scenarios are introduced.

\footnotetext{
${ }^{1}$ http://www.ifremer.fr/sih.htm
} 


\subsection{Species growth functions}

We first aim at representing and quantifying the renewal of the shrimp stock using data from French Guiana. Thus, four population dynamics explicitly integrating the impact of SST are estimated and compared in statistical terms. Although the logistic function is the most widely used in the economic literature, other functions may be considered (Bjørndal, 1988; Clark, 1990; Opsomer and Conrad, 1994; Garza-Gil, 1998; Hannesson, 2006; Nøstbakken, 2008; De Lara and Doyen, 2008). Here four functional forms are tested and compared including logistic, Ricker, Cushing and Cobb-Douglas growth functions. It turns out that the following Cobb-Douglas function best fits the empirical data over the period 1993-2009:

$$
X_{t+1}=a X_{t}^{\alpha_{1}} \theta_{t}^{\alpha_{2}}-H_{t}+\varepsilon_{t}
$$

where the state variable, $X_{t}$, denotes the stock biomass at year $t, H_{t}$ harvest at time $t, \theta_{t}$ the SST at year $t$ and $\varepsilon_{t}$ is the error between the data and the estimated stock assumed to follow a centred Gaussian independent and identically distributed (i.i.d) distribution. Parameters $a, \alpha_{1}$, and $\alpha_{2}$, capture different biological and environmental sensitivities. The statistical results for the Cobb-Douglas function, for which all parameters are significant, are presented in Table 1 . In particular the random variable $\varepsilon_{t}$ follows a Gaussian i.i.d distribution $\mathcal{N}\left(0, \sigma_{X}=0.105\right)$. By contrast, the parameters of the three other growth functions appear not to be significant as reported in Table A2 in the Appendix. The Cobb-Douglas function will thus be used to describe the dynamics of the shrimp stock in the remainder of the paper. Interestingly, the elasticity $\alpha_{2} \approx-8$ with respect to the SST is qualitatively very high and much stronger than the stock elasticity, $\alpha_{1} \approx+1$.

\subsection{The production function}

A commonly-used production function in the theoretical bioeconomic literature about fisheries is the so-called Schaefer form (Schaefer, 1957), where catch depends linearly on both fishing effort and stock. Here, we depart from this approach by considering the Cobb-Douglas form, as in Bjørndal, 1987; Clark, 1990; Bjørndal, 1989; Bjørndal et al., 1993:

$$
H_{t}=b X_{t}^{\beta_{1}} E_{t}^{\beta_{2}}+v_{t},
$$

where $E_{t}$ corresponds to fishing effort at time $t$, and $v_{t}$ is the error between the historical and the estimated catch assumed to follow a centred Gaussian i.i.d. distribution. Parameter $b$ denotes catchability, while coefficients $\beta_{1}$ and $\beta_{2}$ stand for the elasticity of catch $H_{t}$ with respect to biomass $X_{t}$ and effort $E_{t}$ respectively. The effort level corresponds to the total number of days at sea by year. Table 2 displays the estimates of 


\begin{tabular}{lc}
\hline \hline $\ln (a)$ & $X_{t+1}=a X_{t}^{\alpha_{1}} \theta_{t}^{\alpha_{2}}-H_{t}$ \\
$\alpha_{1}$ & $27.03(0.023)$ \\
$\alpha_{2}$ & $1.01(0.000)$ \\
$R^{2}$ & $-8.07(0.022)$ \\
$R^{2}$ adjusted & 0.89 \\
$\sigma_{X}$ Standard error of regression & 0.88 \\
JB Jarque-Bera test for normality & 0.105 \\
Q-Stat Ljung-Box statistic used in the correlation test & 2.69 \\
LM (ARCH) Lagrange multiplier used in the heteroscedasticity test & 6.38 \\
AIC (Akaike) Statistic used in the prediction error model & 1.26 \\
\hline
\end{tabular}

Notes: p-values in parentheses; all coefficients are significant at the $5 \%$ level.

Table 1: Estimates of the Cobb-Douglas natural growth function (1)

the parameters of Equation (2) as applied to the FGSF. Thus, the random variable $v_{t}$ follows a Gaussian distribution $\mathcal{N}\left(0, \sigma_{H}=0.03\right)$. Interestingly, the elasticity of harvest with respect to the stock is very close to one where $\beta_{1}=0.91$ which indicates that production is more sensitive to stock than to fishing effort since $\beta_{2}=0.11$. The accuracy of the calibration is shown in Figure A1 of the Appendix.

\subsection{Fishery management}

Once the model is calibrated from historical data, we can design different long run scenarios from the different drivers impacting dynamics and production, namely fishing intensity $E_{t}$ and SST. Alternatively, one could consider some scenarios based on output control (catches) related to a TAC (total allowable catch), as in European policy (see the 'Discussion' section for more details).. We first focus on different fishing strategies at the time horizon $T=2050$.

Fishing Status Quo: The first strategy, termed 'Status Quo', consists in maintaining the fishing effort at its current level, namely in year $t_{0}=2009$ :

$$
E_{t}=E_{2009}=4,489 \mathrm{das} / \mathrm{y} \quad \text { for } t=2010, \ldots 2050
$$

where das/y stands for 'Days at sea per year'. Such a predictive scenario may can answer the question 'What will likely happen?', as suggested in Potts et al. (2016). 


\begin{tabular}{lc}
\hline \hline & $H_{t}=b X_{t}^{\beta}{ }_{1} E_{t}^{\beta_{2}}$ \\
\hline$b$ & $0.27(0.000)$ \\
$\beta_{1}$ & $0.91(0.000)$ \\
$\beta_{2}$ & $0.11(0.001)$ \\
$\mathrm{R}^{2}$ & 0.99 \\
$\mathrm{R}^{2}$ adjusted & 0.98 \\
$\sigma_{H}$ Standard error of regression & 0.03 \\
F-Stat Fisher statistic & 719 \\
DW Durbin Watson statistic & 1.63 \\
JB Jarque-Bera test for normality & 0.09 \\
\hline
\end{tabular}

Notes: p-values in parentheses; all coefficients are significant at the $5 \%$ level.

Table 2: Estimates of the shrimp harvest function (2)

Closure: The second pattern, denoted as 'Closure', relates to a ban for this shrimp fishery. This reads as follows:

$$
E_{t}=0 \quad \text { for } t=2010, \ldots 2050
$$

Such an exploratory scenario describes an alternative future and aims to answer the question 'What could happen if we stop fishing?'

Maximum Economic Yield strategy: Here we investigate a more normative management strategy based on the intertemporal optimisation of the rent derived from fishing in accordance with the MEY strategy as in Clark (1990). It relates to a situation where the fishery is rationally managed in a centralised manner or with a sole owner or a group of cooperative fishermen. In more mathematical terms, the economic problem of the regulator consists in choosing the effort that maximises the discounted value of the profit flow generated by the production of shrimp,

$$
\pi_{t}=p H_{t}-c E_{t}
$$

where $p$ represents the unit price of harvest while $c$ represents the unit cost of effort. Adopting a risk neutral attitude in the sense that random fluctuations of stock and harvest are not considered in the regulator's computation, the bioeconomic program can thus be written as:

$$
\underset{E_{t}}{\operatorname{Max}} \sum_{t=2010}^{\infty}(1+\mathrm{r})^{-(t-2010)} \pi_{t}
$$




$$
\text { st: } \quad X_{t+1}=a X_{t}^{\alpha_{1}} \theta_{t}^{\alpha_{2}}-b X_{t}^{\beta_{1}} E_{t}^{\beta_{2}}
$$

The solution of the above problem requires the use of optimum control theory (Kamien and Schwartz, 1991). Assuming for a while that the temperature $\theta$ is at equilibrium, it can be proved that the long-term optimal equilibrium is given implicitly by the relation:

$$
\begin{gathered}
{\left[p-A X_{*}^{-\frac{\beta_{1}}{\beta_{2}}}\left(a X_{*}^{\alpha_{1}} \theta^{\alpha_{2}}-X_{*}\right)^{\frac{\left(1-\beta_{2}\right)}{\beta_{2}}}\right]\left(a b X_{*}^{\alpha_{1}-1} \theta^{\alpha_{2}}-1\right) /\left[p-A X_{*}^{-\frac{\beta_{1}}{\beta_{2}}}\left(a X_{*}^{\alpha_{1}} \theta^{\alpha_{2}}\right)^{\frac{\left(1-\beta_{2}\right)}{\beta_{2}}}\right]+} \\
\beta_{1} A X_{*}^{-\frac{\beta_{1}+\beta_{2}}{\beta_{2}}}\left(a X_{*}^{\alpha_{1}} \theta^{\alpha_{2}}-X_{*}\right)^{\frac{1}{\beta_{2}}} /\left[p-A X_{*}^{-\frac{\beta_{1}}{\beta_{2}}}\left(a X_{*}^{\alpha_{1}} \theta^{\alpha_{2}}\right)^{\frac{\left(1-\beta_{2}\right)}{\beta_{2}}}\right]=r
\end{gathered}
$$

where $r=\delta^{-1}-1$ is the discount rate and $\delta$ stands for the discount factor $(0<\delta \leq 1)$, while parameter $A$ equals $A=c\left(b^{\frac{1}{\beta_{2}}} \beta_{2}\right)^{-1}$. The above first order condition obtained in the steady state gives an implicit solution for the stock under MEY. This equation is well known in capital theory as a modified golden-rule equilibrium equation, being modified both by the discount rate and by what we shall refer to as the marginal stock effect. Due to the functional forms of the production and natural growth functions retained, its form is slightly more complicated here than the corresponding standard result in the literature. But it can still be interpreted as follows: the optimal stock is one at which the stock's own growth rate is equal to the social discount rate (Clark and Munro, 1975; Clark, 1990; Bjørndal and Munro, 1998; Conrad, 1999; De Lara and Doyen, 2008). The own rate of interest (left hand side) i.e., the instantaneous marginal sustainable rent divided by the supply price of the asset, consists in the instantaneous marginal physical product of the capital (first term), and the marginal stock effect (second term). The above formula can be interpreted more directly as an investment decision rule, which simply states that one should invest into the resource up to the point where the economic return of marginal investment is equal to the social discount rate. We observe that the optimal value of the shrimp biomass, $X_{*}$, depends on the sea surface temperature and thus we will hereafter denote this optimal biomass level by $X_{*}(\theta)$. The optimal harvest rule can then be deduced from the equilibrium given by Equation (1):

$$
H_{*}(\theta)=a X_{*}(\theta)^{\alpha_{1}} \theta_{t}^{\alpha_{2}}-X_{*}(\theta)
$$

Finally, the effort level can be obtained from the technological constraint Equation (2):

$$
E_{*}(\theta)=\left[\frac{H_{*}(\theta)}{b X_{*}(\theta)^{\beta_{1}}}\right]^{1 / \beta_{2}}
$$


Regarding the numerical values based on the French Guiana case study, the unit price of landings is set at $p=6.60 € / \mathrm{kg}$ (mean output price over the period studied), while the cost per unit of effort is fixed at $c=1900 € /$ day, which corresponds to the mean cost per day at sea. The discount rate is first set at $r=3 \%$. A sensibility analysis related to sustainability will also examine different values ranging from $r=0 \%$ to $r=6 \%$.

\subsection{Climate scenarios}

Each of the last three decades was successively warmer at the Earth's surface than any previous decade since 1850 . The globally averaged and combined land and ocean surface temperatures show a warming of $0.85[0.65 \text { to } 1.06]^{\circ} \mathrm{C}$ over the period 1880 2012 (Pachauri et al., 2014). To analyse the potential effects of global warming on the FGSF between 2010 and 2050, we consider here two IPCC' 'Representative Concentration Pathway' (RCP) scenarios that capture contrasted intensities of global warming. Scenario RCP 2.6 corresponds to the pathway with the lowest greenhouse gas emission levels and thus to the lowest IPCC global warming scenario. It relates to a rise in temperature at an annual rate of about $\Delta_{2.6}=0.01^{\circ} \mathrm{C}$. By contrast, RCP 8.5, the other climate scenario considered here, corresponds to the highest global warming scenario. It is characterized by the highest greenhouse gas emission levels, relating to a warming trend of about $\Delta_{8.5}=0.04^{\circ} \mathrm{C}$ per year. The following dynamics describes the yearly change in the sea surface temperature measured in ${ }^{\circ} \mathrm{C}$ :

$$
\theta_{t+1}=\theta_{t}(1+\Delta), \text { with } \Delta \in\left\{\Delta_{2.6}, \Delta_{8.5}\right\}
$$

which depends on the selected climate scenario and where $\theta_{2009}=28.09^{\circ} \mathrm{C}$ corresponds to the initial condition of scenarios based on the temperature observed in 2009 .

\section{Results}

We now use the statistical estimates of the natural growth and production functions synthesised in Table 3 to simulate the changes in stock, harvest, and profit levels between $t=2010$ and $T=2050$, across both the climate scenarios and the management strategies. Numerical computations are performed with the scientific software ${ }^{2}$ SCILAB 5.4.0. The trajectories of the shrimp stock, harvest and profit are displayed in Figures 1 and 2 according to the selected management strategy and for climate scenarios RCP2.6 and RCP8.5. The grey envelopes in the figures indicate the uncertainties underlying the calibrations of the stock dynamics (Eq.1) and the production function (Eq.2) through random errors $\varepsilon_{t}$ and $v_{t}$.

\footnotetext{
${ }^{2} \mathrm{SCILAB}$ (http://www.scilab.org) is an open-source software program dedicated to scientific calculus and well suited to the simulation of dynamic systems.
} 


\begin{tabular}{|l|l|l|}
\hline & Parameters & Value \\
\hline Production parameters & $b$ & 0.27 \\
& $\beta_{1}$ & 0.91 \\
& $\beta_{2}$ & 0.11 \\
& $\sigma_{H}$ & 0.03 \\
\hline Growth parameters & $a$ & $\exp (27.03)$ \\
& $\alpha_{1}$ & 1.01 \\
& $\alpha_{2}$ & -8.07 \\
\hline Mean output price in $€ / \mathrm{kg}$ & $\sigma_{X}$ & 0.105 \\
\hline Mean cost per unit day in $€ /$ day & $p$ & 6.6 \\
\hline Discount rate & $c$ & 1900 \\
\hline RCP 2.6 in ${ }^{\circ} \mathrm{C}$ & $r$ & 0.03 \\
\hline RCP 8.5 in ${ }^{\circ} C$ & $\Delta_{(2.6)}$ & 0.01 \\
\hline & $\Delta_{(8.5)}$ & 0.04 \\
\hline
\end{tabular}

Table 3: Parameters values

\subsection{Management outcomes with RCP 2.6}

Figure 1 displays the possible trajectories under the lowest warming scenario (RCP 2.6) for the three fishing strategies defined in Section 3 namely Status Quo, Closure, and MEY. First, the Status Quo trajectories show a decline in stock, harvest and profits, pointing out how alarming the current situation of the FGSF is: at the horizon 2050, both the stock and the harvest collapse and profits become negative. Secondly, the Closure strategy is informative regarding stock viability, as Figure 1 shows a first stage of recovery followed by a period of stabilisation by 2050. Thirdly, concerning MEY bioeconomic performance, although there is a decline similar to the Status Quo, it is less pronounced. The profit remains strictly positive, while the stock at MEY is strictly larger than zero, suggesting a bioeconomic viability situation.

\subsection{Management outcomes with RCP 8.5}

As can be seen in Figure 2, the highest global warming scenario (RCP 8.5) turns out to be very alarming, at least by year 2050, since the biomass, catch, and rents decline and are jeopardized in the long run, regardless of the management strategy adopted. The Status Quo strategy, which consists in maintaining the fishing effort intensity observed in 2009, results in the worst effects on the fishery, since it never allows the stock to recover and leads to a fall in catch and negative profits from the early 2020s. The Closure strategy enable the rebuilding of the stock until 2030, but its erosion is again significant by 2050 , contrary to what occurs in the RCP 2.6 scenario, where the stock 

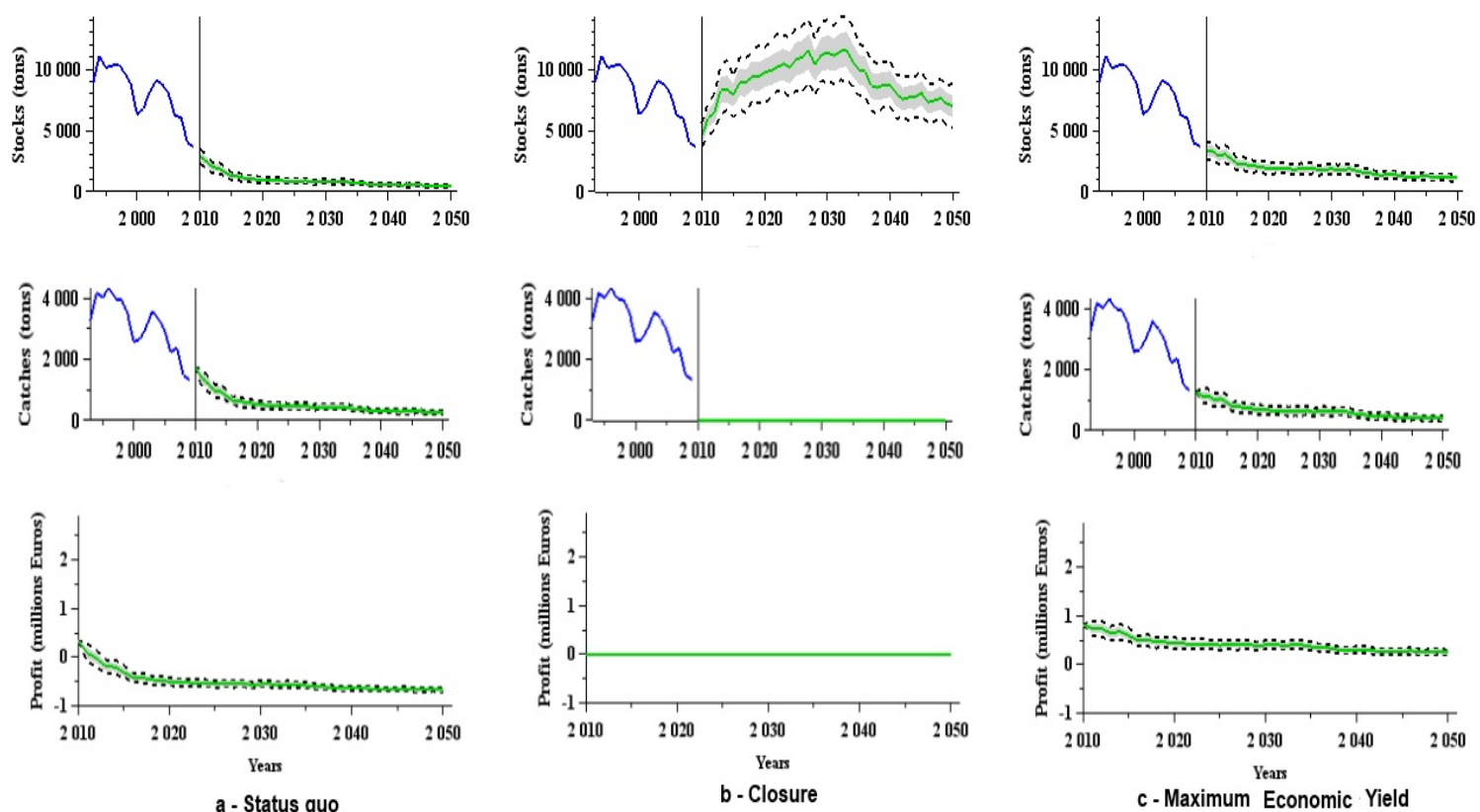

Figure 1: Trajectories for stock, catch and profit, under the RCP 2.6 climate scenario and fishing strategies: a-Status Quo, b-Closure, c-Maximum Economic Yield. Blue lines represent historical trajectories, green lines represent median trajectories, and dotted lines represent the $95 \%$ confidence intervals. 
stabilizes by 2030. In contrast to the Status Quo, the MEY strategy allows for positive profits over the entire projection period, even if they tend to zero around 2050.
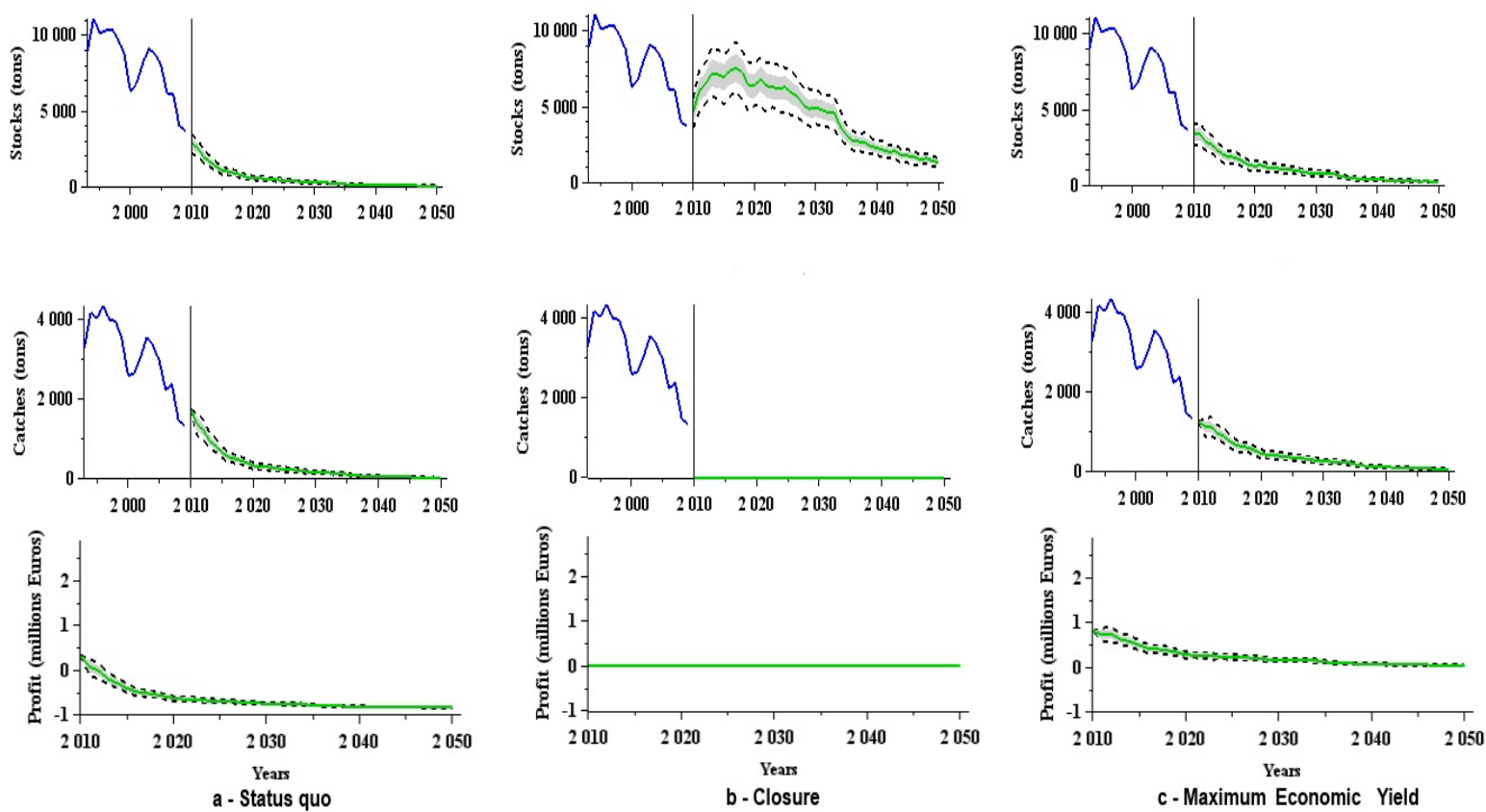

Figure 2: Trajectories for stock, catch and profit, under the RCP 8.5 climate scenario and fishing strategies: a-Status Quo, b-Closure, c-Maximum Economic Yield. Blue lines represent historical trajectories, green lines represent median trajectories and dotted lines represent the $95 \%$ confidence intervals.

\subsection{Sensitivity of Maximum Economic Yield gains with respect to discount rate}

In Table 4, the bioeconomic gains of the MEY fishing strategy, as compared to the Status Quo are evaluated at the time horizon $\mathrm{T}=2050$ with respect to the discount rate $r$. 'Bioeconomic gains of MEY' refers to the difference between MEY and Status Quo (SQ) scores in terms of mean stock, harvest and net present value namely:

$$
X_{2050}^{M E Y}-X_{2050}^{S Q} ; H_{2050}^{M E Y}-H_{2050}^{S Q} ; \sum_{t} \rho^{t} \pi_{t}^{M E Y}-\sum_{t} \rho^{t} \pi_{t}^{S Q}
$$

where $X^{M E Y}, H^{M E Y}, \pi^{M E Y}$ stand for expected $\left(\varepsilon_{t}=0, v_{t}=0\right)$ outputs for the MEY fishing strategy, while $X^{S Q}, H^{S Q}, \pi^{S Q}$ are the same expected metrics for the Status Quo harvesting strategy. Table 4 demonstrates that the lower the discount rate, the 


\begin{tabular}{|l|l|l|l|l|l|l|l|}
\hline \hline & $\mathrm{r}=0 \%$ & $\mathrm{r}=1 \%$ & $\mathrm{r}=2 \%$ & $\mathrm{r}=3 \%$ & $\mathrm{r}=4 \%$ & $\mathrm{r}=5 \%$ & $\mathrm{r}=6 \%$ \\
\hline Gain of stock at 2050 for RCP 2.6 (in tons) & 891 & 871 & 863 & 748 & 693 & 676 & 664 \\
\hline Gain of stock at 2050 for RCP 8.5 (in tons) & 336 & 326 & 314 & 279 & 285 & 236 & 220 \\
\hline Gain of harvest at 2050 for RCP 2.6 (in tons) & 207 & 204 & 199 & 201 & 205 & 203 & 198 \\
\hline Gain of harvest at 2050 for RCP 8.5 (in tons) & 35.1 & 35.2 & 35.2 & 35.6 & 35.9 & 33.4 & 33 \\
\hline Gain of NPV at 2050 for RCP 2.6 (in ke) & 9,467 & 9,185 & 9,186 & 9,189 & 9,169 & 9,104 & 9,127 \\
\hline Gain of NPV at 2050 for RCP 8.5 (in ke) & 8,886 & 8,796 & 8,883 & 8,869 & 8,856 & 8,819 & 8,807 \\
\hline
\end{tabular}

Table 4: Sensitivity analysis of ecological-economic gains between MEY and Status Quo harvesting strategies with respect to discount rate $r$

larger the bioeconomic gains for the stock, the harvest and the net present value at time horizon $\mathrm{T}=2050$. We can observe that the gains of MEY (versus $\mathrm{SQ}$ ) with respect to the discount rate are especially important for the stock at time horizon 2050. For instance for the RCP 2.6 climate scenario, the relative difference of stock between $r=0 \%$ and $r=6 \%$ equals $(891-664) / 664 \approx 34 \%$ (values in red in Table 4 ). In other words, we confirm here the positive role the discount rate plays on sustainability. A discount rate of $r=0$ balancing present and future equally is more relevant to reinforcing ecological and economic viability. We also note that these bioeconomic gains are larger with RCP 2.6 than with RCP 8.5. The difference between the climate scenarios is massive for the stock and the harvest. For instance, the relative difference is $(207-35) / 35 \approx 500 \%$ for harvest at $t=2050$ at discount rate $r=0 \%$.

\section{Discussion}

\subsection{The bioeconomic vulnerabilities of the French Guiana shrimp fishery}

The results show that the Status Quo strategy for the FGSF leads to the collapse of the fishery in the long run. Both RCP climate scenarios confirm such an alarming outcome, which is consistent with the historical decline of the fishery over the past two decades. The two mechanisms underlying this bioeconomic vulnerability are as follows: First, according to the production function (2), the fall in harvest is strongly influenced by a decrease in the stock, as the elasticity of harvest $\beta_{1}=0.91$ with respect to the stock is significantly higher than the elasticity of harvest $\beta_{2}=0.11$ with respect to effort. Bjørndal and Brasão (2006) mention a similar situation for the East Atlantic blue fin tuna fishery. Secondly, the negative impact on stock dynamics of global warming scenarios through the rise in SST is very strong since the elasticity $\alpha_{2} \approx-8$ with respect to the SST is qualitatively very high and much stronger than stock elasticity $\alpha_{1} \approx+1$. In 
other words, a rise in the temperature strongly alters stock renewal. The combination and interplay of the two previous negative mechanisms significantly explain the major decline in both shrimp catches and stocks as well as the bioeconomic collapse of the fishery in the long run, whenever fishing effort is kept at its current level. The direct negative effect of the rise in SST on stock dynamics is thus considerably stronger than the positive effect of the decrease in harvest induced by the decline of the stock. The above results indicate that SST might be the strongest negative driver of change in the FGSF in the future. Such an environmental vulnerability is also exemplified by the Closure (fishing ban) strategy, where it can be observed that after an initial period of recovery for the shrimp biomass, the stock declines again from 2030. Such an erosion in the long run is especially emphasised in the case of the worst climate scenario RCP 8.5. Such alarming performance can be explained mainly by the fact that SST influences shrimp habitat change. Notably, recent works on the characterisation of the habitat of Farfantepenaeus subtilis have shown that the optimal surface temperature observed within the distribution area of the species ranges from $27.07^{\circ} \mathrm{C}$ to $28.32^{\circ} \mathrm{C}$ (Kaschner et al., 2013). In the same vein, Lopes et al. (2018) explain how shrimp fishing productivity is affected by environmental factors such as SST in Brazilian waters. Between 1993 and 2009, our study period, SSTs in French Guiana twice exceeded the maximum viable value in 1998 and 2005. This suggests that biological functions including growth, maturation and survival deteriorated at those times. Considering the forecasting period and a fishing effort scenario at status quo, the maximum viable value is permanently exceeded in 2019. Hence, the decrease in the stock for the scenarios seems to be consistent with the previous statement. Similar negative patterns seem to occur in other shrimp fisheries worldwide as in de Lange (2013) for the US.

\subsection{Maximum Economic Yield to adapt to global warming}

The results along with Figures 1 and 2 also show that the MEY management strategy could contribute to mitigating the negative effects of climate change on the FGSF. Indeed, the MEY strategies, under both climate scenarios, do enable stock and profit levels to become viable, although this bioeconomic viability is achieved at low levels of stock, effort, catch and profit for the worst climate scenario, RCP 8.5. The mechanisms underlying such outputs are twofold. First, by focusing on the profitability of the fishery over time through maximisation of the net present value, such a MEY strategy clearly promotes economic scores for the fishery, and in particular performs better than the status quo in terms of profitability over time. More interestingly, such an economic rationality also includes the viability of the stock, as already pointed out in many works including Clark (1990). In that sense, the paper confirms that MEY makes it possible to combine ecological and economic performance. The second mechanism underlying the positive outcomes of MEY scenarios in this paper draws on the adaptiveness of the strategy implemented here. The optimal harvesting strategy defined in Equation (9) 
depends on climate proxy $\theta$ and thus fishing effort changes over time according to the value of the uncertain temperature $\theta_{t}$ and the induced stock $X_{t}$. In that sense, such a MEY strategy constitutes a successful bioeconomic adaptation to climate change for the FGSF. Such a result is in line with Ogier et al. (2016) who highlight the need for institutional arrangements favouring adaptive management in order to adress climate change.

Moreover the sensitivity analysis with respect to the discount rate $r$ displayed in Table 4 puts forward the gains of MEY in terms of sustainability, as the synergy between ecological and economic performance is reinforced when the discount rate is close to 0 , balancing the present and the future in a more relevant way. To go further the use of maximin or viability criteria and strategies (Doyen and Martinet, 2012) should constitute relevant alternatives.

\subsection{Implementing the MEY strategy}

The MEY strategy is known to offer certain advantages in terms of strong sustainability (ecological and economic viability). However, implementing such a strategy raises several issues. First, MEY is a moving target, since it changes according to predictions relating to costs and prices, as underlined by Kompas et al. (2010). As far as the FGSF is concerned, a MEY target would thus raise several concerns, because fishermen are price takers in the world shrimp market. For the past two decades, French Guiana shrimp have been sold in the same market as the farmed production from South East Asia. The French Guiana shrimp price has thus been strongly correlated with South East Asia prices, which have been very low due to high output levels and low labour costs. Both the above effects have driven the French Guiana shrimp price down. Furthermore, the price of fuel, which represents up to $25 \%$ of overall production costs in French Guiana, has strongly increased over the same period.

Secondly, implementing MEY may not be well understood by managers, or aiming to achieve its objectives may imply selecting effort trajectories that would not be acceptable to the industry, as put forward by (Dichmont et al., 2010). One solution to the latter problem could consist in implementing large-scale buyback programmes as part of the transition process towards MEY targets, such as in Commonwealth fisheries in 2006 (Pascoe et al., 2016).

All in all, the three strategies considered in this paper could appear somewhat extreme or rigid, and do not allow much leeway for public intervention. Only the strategy of simply closing the FGSF enables the stock to be conserved, whereas the two other strategies (Status Quo and MEY) lead to unsatisfactory results (profits with MEY are also very low). In order to avoid the closure of the FGSF, an alternative intermediate strategy could consist in partially closing it and managing the closed part as a marine protected area, while continuing to exploit the remainder of the fishery with the help of the MEY strategy, as mentioned in Dichmont et al. (2013). 
The emphasis in this article has been on fishing effort control. The disadvantages of regulations that rely on input control, especially situations where technology creep impacts fishing effort and fishing mortality, are well known (Wilen, 1979). Moreover, apart from the different strategies that are already considered in this paper, a TAC system or transferable quotas could constitute alternative management tools, as underlined by Doyen et al. (2017). The consequences of such a possibility in the FGSF have already been analysed by Chaboud and Thebaud (2009).

\section{Conclusion}

This paper addresses the impacts of global warming on fishery management and ecologicaleconomic performance. To achieve this, fishing strategies and IPCC climate scenarios are assessed through a dynamic bioeconomic model in which the stock's growth function depends on the SST. The model is empirically quantified and statistically validated for the French Guiana shrimp fishery (FGSF) using time series over the period 1993-2009. Such a case study is challenging, because the shrimp stock is declining despite strong reductions in fishing effort over the past two decades. The negative role of external drivers including climate warming is thus put forward (Sanz et al., 2017).

The contribution of the paper is threefold. The first major contribution, through projective scenarios, consists in pointing out the ecological economic vulnerabilities of the FGSF due to SST warming. Such vulnerabilities emerge especially when fishing intensity is maintained at its current level with the Status Quo fishing strategy. The second important contribution of the paper relates to the bioeconomic merits of MEY policies for fisheries facing climate change. In particular, the adaptive MEY fishing effort computed and implemented here paves the ways for a reduction in bioeconomic vulnerabilities by the adaptation of fishery management policies in the context of global warming. The paper confirms that MEY promotes sustainability by increasing the compatibility between ecological and economic goals. Such synergies are especially reinforced when the discount rate is close to zero and favours intergenerational equity and therefore sustainability. The third important contribution of the paper is that it provides insights into the operationalisation of the ecosystem-based management approach for fisheries, which takes into account the ecological and economic complexities associated with climate drivers (Link et al., 2017). Our analysis thus confirms the advantages of adopting an ecosystem-based management approach, which systematically integrates environmental drivers including those related to global warming, in order to take into account their impact on the growth of the stock of harvested species and the economic performance of fisheries.

As Stock et al. (2011), de Lange (2013), and Lopes et al. (2018) put forward, exploring the influence of climate change on marine resource dynamics is a key issue. In that regard, the paper shows how to take SST into account in ecological-economic dynamic 
modelling, scenarios and more specifically MEY management using rigorous statistical methods for the calibration of the models used.

However, under the pessimistic RCP 8.5 climate scenario, the MEY adaptive strategy, despite making it possible to avoid catastrophic bioeconomic outputs and mitigate vulnerabilities, does not provide satisfactory performance, as optimal stock, effort, catch, and profit are very low in the long run. In other words, MEY turns out to be a relevant bioeconomic strategy in terms of adaptation to climate change and sustainability, but only in connection with climate change mitigation. Thus the study developed in this paper also confirms that climate change management is essential to the sustainable development of fisheries and marine ecosystems (Brander, 2007; Cheung et al., 2009). In that respect, the case of tropical fisheries is especially challenging, since only a few species can find colder sea areas, which is not the case for shrimp.

Acknowledgments. This work was carried out with financial support from the Belmont Forum through its funding of the SEAVIEW network (ANR-14-JPF1-0003), as well as from the VOGUE, ECOPE (PIG CNRS), OYAMAR (FEDER), and ACROSS (ANR-14-CE03-0001) research projects. 


\section{A Appendix}

\section{A.1 Details of the numerical computation}

This appendix presents the observed and adjusted catches of the FGSF over the period 1993-2009. The changes observed and adjusted catch values are depicted in Figure A1 below.

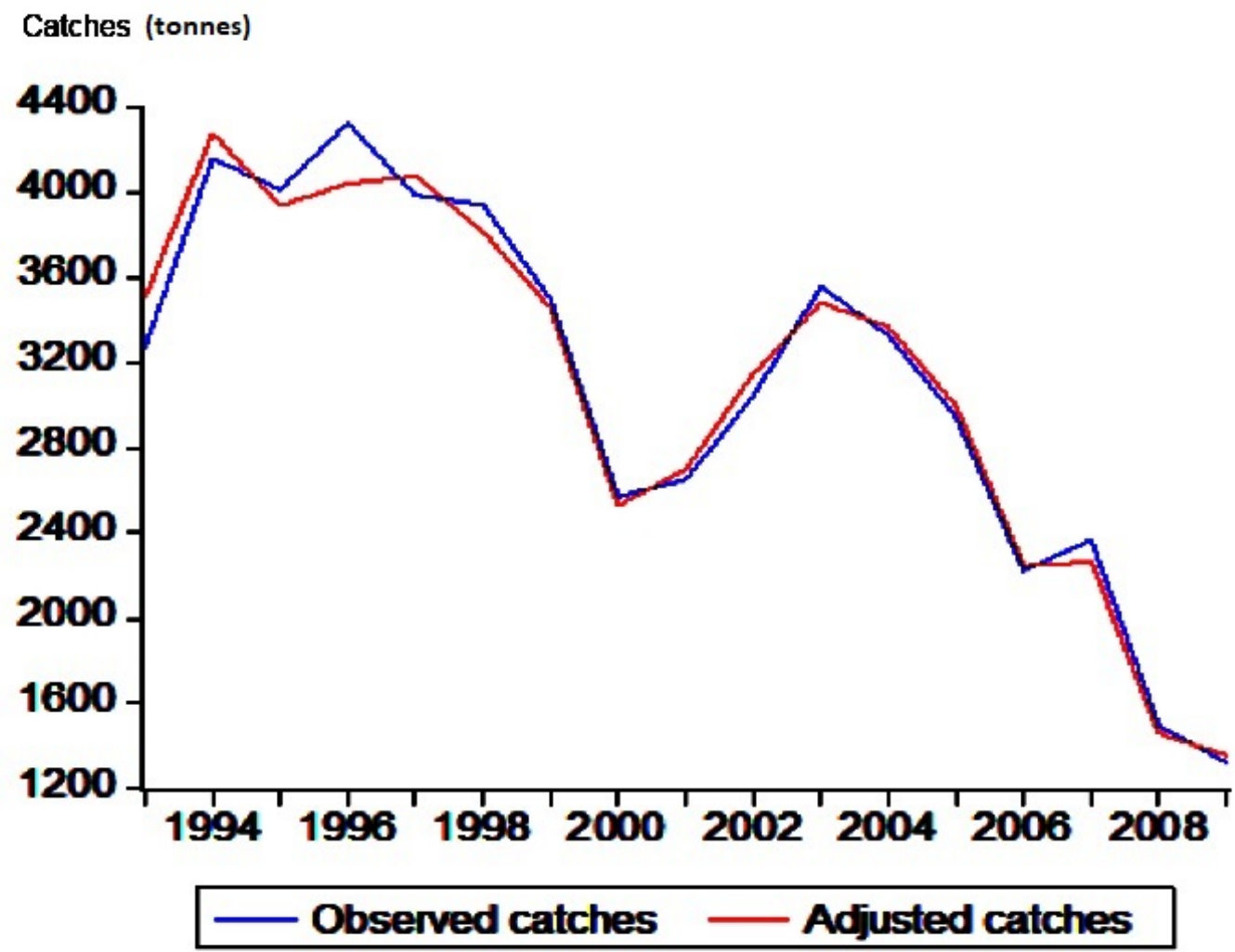

Figure A1: Observed vs Adjusted catches 


\section{A.2 Data set}

In this appendix, Table A1 describes historical data collected by Ifremer on the FGSF and SST over the period 1993-2009. Biomass, catches and effort decrease simultaneously while SST rises over the same period.

\begin{tabular}{|l|l|l|l|l|}
\hline \hline Year & Biomass (tons) & Total catches (tons) & Effort (days of fishing) & Sea surface temperature $\left({ }^{\circ} c\right)$ \\
\hline 1993 & 8929 & 3275 & 15,682 & 27.57 \\
\hline 1994 & 11126 & 4156 & 15,154 & 27.77 \\
\hline 1995 & 10120 & 4010 & 15,723 & 27.87 \\
\hline 1996 & 10303 & 4323 & 17,116 & 27.86 \\
\hline 1997 & 10409 & 3984 & 16,992 & 27.66 \\
\hline 1998 & 9739 & 3940 & 16,320 & 28.43 \\
\hline 1999 & 8765 & 3495 & 16,013 & 27.94 \\
\hline 2000 & 6302 & 2572 & 14,764 & 27.80 \\
\hline 2001 & 6809 & 2651 & 14,026 & 27.67 \\
\hline 2002 & 8120 & 3043 & 13,058 & 27.72 \\
\hline 2003 & 9110 & 3557 & 12,504 & 28.08 \\
\hline 2004 & 8778 & 3325 & 12,550 & 28.16 \\
\hline 2005 & 8026 & 2943 & 9,266 & 28.37 \\
\hline 2006 & 6173 & 2222 & 6,141 & 27.94 \\
\hline 2007 & 6096 & 2369 & 7,278 & 28.02 \\
\hline 2008 & 4000 & 1496 & 4,667 & 28.05 \\
\hline 2009 & 3705 & 1323 & 4,489 & 28.09 \\
\hline
\end{tabular}

Table A1: Data collected for the shrimp fishery and SST over the period 1993-2009

\section{A.3 Details of the estimation of other natural growth functions}

This appendix presents the details of the estimation of the three other growth functions tested to fit French guianese shrimp. The above three functional forms are known as logistic, Ricker and Cushing natural growth functions, respectively. Estimation of the parameters using the data shown in Table A1 and their comparisons in statistical terms are depicted in Table A2.

$$
\begin{gathered}
X_{t+1}=a X_{t}+\alpha_{1} X_{t}^{2}+\alpha_{2} \theta_{t}-H_{t} \\
X_{t+1}=a X_{t} e^{\alpha_{1} X_{t}+\alpha_{2} \theta_{t}}-H_{t} \\
X_{t+1}=a X_{t}^{\alpha_{1}+\alpha_{2} \theta_{t}}-H_{t}
\end{gathered}
$$




\begin{tabular}{lccc}
\hline \hline & $X_{\mathrm{t}+1}+h_{t}=a X_{t}^{\alpha_{1}+\alpha_{2} \theta_{t}}$ & $X_{t+1}+h_{t}=a X_{t}+\alpha_{1} X_{t}^{2}+\alpha_{2} \theta_{t}$ & $X_{t+1}+h_{t}=a X_{t} e^{\alpha_{1} X_{t}+\alpha_{2} \theta_{t}}$ \\
\hline$a$ & $0.13(0.884)$ & $2.10(0.055)$ & $1.19(0.105)$ \\
$\ln (a)$ & $1.89(0.000)$ & $-4.17 \mathrm{E}-05(0.478)$ & $6.80(0.295)$ \\
$\alpha_{1}$ & $-0.03(0.024)$ & $-104.48(0.414)$ & $-2.15 \mathrm{E}-05(0.794)$ \\
$\alpha_{2}$ & 0.89 & 0.82 & $-0.28(0.027)$ \\
$R^{2}$ & 0.87 & 0.80 & 0.89 \\
$R^{2}$ adjusted & & 0.87
\end{tabular}

Notes: p-values between brackets

Table A2: Estimates of the Cushing, logistic, and Ricker natural growth functions 


\section{References}

Béné, C. and L. Doyen (2000), 'Storage and viability of a fishery with resource and market dephased seasonalities', Environmental and Resource Economics 15: 1-26.

Bernard, C. (2006), Changement climatique, conséquences potentielles pour la biodiversité ichtyologique et pour la pêche côtière en Guyane française entre 1970 et 2005, Master's thesis, Université La Rochelle.

Bjørndal, T. (1987), 'Production economics and optimal stock size in a North Atlantic fishery', The Scandinavian Journal of Economics : 145-164.

Bjørndal, T. (1988), 'The optimal management of North Sea herring', Journal of Environmental Economics and Management 15: 9-29.

Bjørndal, T. (1989), 'Production in a schooling fishery: The case of the North Sea herring fishery', Land Economics 65: 49-56.

Bjørndal, T. and A. Brasão (2006), 'The East Atlantic bluefin tuna fisheries: stock collapse or recovery?' Marine Resource Economics 21: 193-210.

Bjørndal, T., J. M. Conrad, and K. G. Salvanes (1993), 'Stock size, harvesting costs, and the potential for extinction: the case of sealing', Land Economics : 156-167.

Bjørndal, T. and G. Munro (1998), 'The economics of fisheries management: a survey.' International Yearbook of Environmental and Resource Economics : 153-188.

Brander, K. M. (2007), 'Global fish production and climate change', Proceedings of the National Academy of Sciences 104: 19709-19714.

Chaboud, C. and O. Thebaud (2009), 'Bioeconomic model of the dynamics of fisheries facing global economic and environment changes: the French Guyana shrimp fishery', in The 18th World IMACS Congress and MODSIM09 International Congress on Modelling and Simulation. Cairns, Australia from 13-17 July 2009.

Cheung, W. W., V. W. Lam, J. L. Sarmiento, K. Kearney, R. Watson, and D. Pauly (2009), 'Projecting global marine biodiversity impacts under climate change scenarios', Fish and Fisheries 10: 235-251.

Clark, C. W. (1990), Mathematical bioeconomics: the optimal management of renewable resources, Wiley-New York.

Clark, C. W. (2010), Mathematical bioeconomics: the mathematics of conservation, volume 91, John Wiley \& Sons. 
Clark, C. W. and G. R. Munro (1975), 'The economics of fishing and modern capital theory: a simplified approach', Journal of environmental economics and management 2: $92-106$.

Conrad, J. M. (1999), 'The bioeconomics of marine sanctuaries', Journal of Bioeconomics 1: 205-217.

de Lange, C. (2013), 'Fishery forced to close as shrimp stocks collapse', New Scientist 220: 7 .

De Lara, M. and L. Doyen (2008), Sustainable management of natural resources: mathematical models and methods, Springer Science \& Business Media.

Dichmont, C., S. Pascoe, T. Kompas, A. E. Punt, and R. Deng (2010), 'On implementing maximum economic yield in commercial fisheries', Proceedings of the National Academy of Sciences 107: 16-21.

Dichmont, C. M., N. Ellis, R. H. Bustamante, R. Deng, S. Tickell, R. Pascual, H. LozanoMontes, and S. Griffiths (2013), 'EDITOR'S CHOICE: evaluating marine spatial closures with conflicting fisheries and conservation objectives', Journal of Applied Ecology 50: $1060-1070$.

Doyen, L., C. Béné, M. Bertignac, F. Blanchard, A. A. Cissé, C. Dichmont, S. Gourguet, O. Guyader, P.-Y. Hardy, S. Jennings, L. R. Little, C. Macher, D. J. Mills, A. Noussair, S. Pascoe, J.-C. Pereau, N. Sanz, A.-M. Schwarz, T. Smith, and O. Thébaud (2017), 'Ecoviability for ecosystem-based fisheries management', Fish and Fisheries 18: 10561072 .

Doyen, L. and V. Martinet (2012), 'Maximin, viability and sustainability', Journal of Economic Dynamics and Control 36: 1414-1430.

FAO (2016), The state of world fisheries and aquaculture, State of World Fisheries and Aquaculture (FAO), Rome. 200 pp.

Garandeau, C. (2006), Les comptes économiques de la Guyane en 2015. La baisse de l'investissement ralentit la croissance, INSEE Antilles Guyane.

Garza-Gil, M. D. (1998), 'ITQ systems in multifleet fisheries', Environmental and Resource Economics 11: 79-92.

Garza-Gil, M. D., J. Torralba-Cano, and M. M. Varela-Lafuente (2011), 'Evaluating the economic effects of climate change on the European sardine fishery', Regional Environmental Change 11: 87-95. 
Grafton, Q. R., T. Kompas, T. N. Che, L. Chu, and R. Hilborn (2012), 'BMEY as a fisheries management target', Fish and Fisheries 13: 303-312.

Grafton, R. Q., T. Kompas, L. Chu, and N. Che (2010), 'Maximum economic yield', Australian Journal of Agricultural and Resource Economics 54: 273-280.

Grafton, R. Q., T. Kompas, and R. W. Hilborn (2007), 'Economics of overexploitation revisited', Science 318: 1601-1601.

Hannesson, R. (2006), 'Sharing the Northeast Arctic cod: possible effects of climate change', Natural Resource Modeling 19: 633-654.

Kamien, M. I. and N. L. Schwartz (1991), 'Dynamic optimisation', The calculus of variations and optimal control in economics and management (second edition) North Holland, New York.

Kaschner, K., J. Rius-Barile, K. Kesner-Reyes, C. Garilao, S. Kullander, T. Rees, and R. Froese (2013), 'AquaMaps', Predicted range maps for aquatic species World Wide Web electronic publication, Version 8: 2013.

Kompas, T., C. M. Dichmont, A. E. Punt, A. Deng, T. N. Che, J. Bishop, P. Gooday, Y. Ye, and S. Zhou (2010), 'Maximizing profits and conserving stocks in the Australian Northern Prawn Fishery', Australian Journal of Agricultural and Resource Economics 54: 281-299.

Larkin, P. A. (1977), 'An epitaph for the concept of maximum sustained yield', Transactions of the American fisheries society 106: 1-11.

Lehodey, P., J. Alheit, M. Barange, T. Baumgartner, G. Beaugrand, K. Drinkwater, J.-M. Fromentin, S. Hare, G. Ottersen, R. Perry et al. (2006), 'Climate variability, fish, and fisheries', Journal of Climate 19: 5009-5030.

Levitus, S., J. I. Antonov, T. P. Boyer, and C. Stephens (2000), 'Warming of the world ocean', Science 287: 2225-2229.

Link, J. S., H. L. Tolman, and K. Robinson (2017), 'Earth systems: NOAA's strategy for unified modelling', Nature 549: 458-458.

Lopes, P. F. M., M. G. Pennino, and F. Freire (2018), 'Climate change can reduce shrimp catches in equatorial Brazil', Regional Environmental Change 18: 223-234.

Mace, P. M. (2001), 'A new role for MSY in single-species and ecosystem approaches to fisheries stock assessment and management', Fish and fisheries 2: 2-32. 
Moffitt, C. M. and L. Cajas-Cano (2014), 'Blue growth: the 2014 FAO state of world fisheries and aquaculture', Fisheries 39: 552-553.

Nøstbakken, L. (2008), 'Stochastic modelling of the North Sea herring fishery under alternative management regimes', Marine Resource Economics 23: 65-86.

Ogier, E. M., J. Davidson, P. Fidelman, M. Haward, A. J. Hobday, N. J. Holbrook, E. Hoshino, and G. T. Pecl (2016), 'Fisheries management approaches as platforms for climate change adaptation: Comparing theory and practice in Australian fisheries', Marine Policy 71: 82-93.

Opsomer, J.-D. and J. M. Conrad (1994), 'An open-access analysis of the northern anchovy fishery', Journal of Environmental Economics and Management 27: 21-37.

Pachauri, R. K., M. R. Allen, V. R. Barros, J. Broome, W. Cramer, R. Christ, J. A. Church, L. Clarke, Q. Dahe, P. Dasgupta et al. (2014), Climate change 2014: synthesis report. Contribution of Working Groups I, II and III to the fifth assessment report of the Intergovernmental Panel on Climate Change, IPCC.

Pascoe, S., V. Kahui, T. Hutton, and C. Dichmont (2016), 'Experiences with the use of bioeconomic models in the management of Australian and New Zealand fisheries', Fisheries research 183: 539-548.

Pikitch, E., C. Santora, E. Babcock, A. Bakun, R. Bonfil, D. Conover, P. Dayton, others, P. Doukakis, D. Fluharty, B. Heneman et al. (2004), 'Ecosystem-based fishery management', Science 305: 346-347.

Potts, S., V. Imperatriz-Fonseca, H. Ngo, J. Biesmeijer, T. Breeze, L. Dicks, L. Garibaldi, R. Hill, J. Settele, and A. Vanbergen (2016), 'IPBES (2016): Summary for policymakers of the assessment report of the Intergovernmental Science-Policy Platform on Biodiversity and Ecosystem Services on pollinators, pollination and food production', Secretariat of the Intergovernmental Science-Policy Platform on Biodiversity and Ecosystem Services Bonn, Germany .

Sanchirico, J. N., M. D. Smith, and D. W. Lipton (2008), 'An empirical approach to ecosystem-based fishery management', Ecological Economics 64: 586-596.

Sanz, N., B. Diop, F. Blanchard, and L. Lampert (2017), 'On the influence of environmental factors on harvest: the French Guiana shrimp fishery paradox', Environmental Economics and Policy Studies 19: 233-247.

Schaefer, M. B. (1957), 'A study of the dynamics of the fishery for yellowfin tuna in the eastern tropical Pacific Ocean', Inter-American Tropical Tuna Commission Bulletin 2: $243-285$. 
Steinmetz, F., O. Thébaud, F. Blanchard, P. Le Floch, and J. Bihel (2008), 'A bioeconomic analysis of long term changes in the production of French fishing fleets operating in the Bay of Biscay', Aquatic Living Resources 21: 317-327.

Stock, C. A., M. A. Alexander, N. A. Bond, K. M. Brander, W. W. Cheung, E. N. Curchitser, T. L. Delworth, J. P. Dunne, S. M. Griffies, M. A. Haltuch, J. A. Hare, A. B. Hollowed, P. Lehodey, S. A. Levin, J. S. Link, K. A. Rose, R. R. Rykaczewski, J. L. Sarmiento, R. J. Stouffer, F. B. Schwing, G. A. Vecchi, and F. E. Werner (2011), 'On the use of IPCC-class models to assess the impact of climate on Living Marine Resources', Progress in Oceanography 88: $1-27$.

Thébaud, O., L. Doyen, J. Innes, M. Lample, C. Macher, S. Mahévas, C. Mullon, B. Planque, M. Quaas, T. Smith, and Y. Vermard (2014), 'Building ecologicaleconomic models and scenarios of marine resource systems: Workshop report', Marine Policy 43: $382-386$.

Wilen, J. E. (1979), 'Fisherman behavior and the design of efficient fisheries regulation programs', Journal of the Fisheries Board of Canada 36: 855-858.

Worm, B., R. Hilborn, J. K. Baum, T. A. Branch, J. S. Collie, C. Costello, M. J. Fogarty, E. A. Fulton, J. A. Hutchings, S. Jennings, O. P. Jensen, H. K. Lotze, P. M. Mace, T. R. McClanahan, C. Minto, S. R. Palumbi, A. M. Parma, D. Ricard, A. A. Rosenberg, R. Watson, and D. Zeller (2009), 'Rebuilding Global Fisheries', Science 325: $578-585$.

Yimin, Y., C. Kevern, B. Gabriella, W. Rolf, M. Jacek, T. Merete, and C. Fabio (2013), 'Rebuilding global fisheries: the World Summit Goal, costs and benefits', Fish and Fisheries 14: 174-185. 